\title{
Investigating a Scaffold to Code-Switching as Strategy in Multilingual Classrooms
}

\author{
Hannatjie Vorster \\ North-West University (Potchefstroom Campus) \\ hannatjie.vorster@nwu.ac.za
}

There is an urgent need to find strategies to assist multilingual learners who are taught by means of English as the language of teaching and learning (LoLT) in coping with subject matter, especially as learners show different levels of English proficiency. One important strategy is code-switching. The possibility of using a glossary, notes and tests given in English and Setswana as scaffold for the code-switching, was investigated in a qualitative study. An intervention was launched in a region where the main language is Setswana. Two schools participated in the study, one school in a rural area and the other in a township. The teaching of a geometry unit was undertaken in which notes, a glossary and tests in English and Setswana were used to assist the learners. The teachers used a strategy of code-switching. Interviews with the learners and the teachers revealed that learners had a positive attitude towards the use of both languages in written work. In contrast, the teachers had mixed feelings, especially about the use of mathematical terminology in Setswana. Difficulties experienced and positive features regarding the use of new Setswana terminology are discussed.

The use of two or more languages, usually English and an indigenous language, has now become a recognised feature in multilingual classes in South Africa. Code-switching, as this phenomenon has become known, has however been introduced in an informal and unstructured manner. In teacher education in South Africa pedagogy that includes language strategies in the teaching and learning of mathematics is still in its infancy. Research carried out in the North West region in South Africa (NWSA) has indicated that although oral codeswitching was used widely, no written material was made available for learners in their own language to refer to when they did homework or studied for tests (Vorster, 2005). This study attempts to contribute to the search for ways to support learners in the use of their main language in combination with English to enhance conceptualisation in mathematics. The term 'learners' main language' refers to the indigenous language in which the learner is the most proficient. Due to environmental influences, this may be a different language than the learner's original home language.

A brief discussion of literature is given to motivate why the main language of the learner is so important for conceptualisation. An overview of the current language strategies, techniques and the different language scenarios in the classroom in South Africa is also crucial to a valid contribution.

\section{Theoretical background}

The role of language in the learning of mathematics The importance of language for conceptualisation and reasoning in general and for mathematics in particular, has long been acknowledged in the research literature (Gentner \& Goldin-Meadow, 2003; Pimm, 1987, 1991; Usiskin, 1996; Vygotsky, 1962). The following can be highlighted: When new concepts are constructed, word sense plays an important role. The "sense" of a word is understood to be all that a word arouses in our consciousness and all the different nuances of the meaning of a word in different contexts (Vygotsky, 1962). Mastery of word sense is important for understanding concepts. Word sense is only mastered in a specific language when the proficiency of the learner has reached a certain level. According to Khisty (1995), the development of proficiency in the disciplinary register within the second language can take as long as seven years. In rural areas with an English foreign language environment, it may take longer. 
The Network Theory of Learning stresses the importance of connecting new knowledge into networks of existing knowledge in order for conceptualisation to occur (Shunk, 1996). Conceptual knowledge embedded in the learner's main language forms important prior knowledge. This, together with word sense that is usually well developed in the main language of a learner, gives an indication that the main language plays a crucial role in facilitating the construction of learners' concepts.

Usiskin (1996) stresses that oral communication, both formal and informal, is important for the learning of mathematics. By articulating their mathematical ideas and discussing it with peers, learners negotiate mathematical meaning for themselves (Costello, 1991; Pimm, 1987; Sai, 1994). The main language of learners supplies a support system to facilitate the interaction among learners and with the teacher, while their proficiency in English is developed (Khisty, 1995; Setati, et al., 2002).

Part of learning mathematics entails gaining control over its register. It poses problems even for first language learners because of the specific structure of the mathematics register (Pimm, 1991), and all the more so for second language learners. Learners struggle with the specific and correct use of prepositions, the numerous synonyms in English as well as with the fact that many words have different meanings in Standard English and the mathematics register (Orton \& Frobisher, 1996; Pimm, 1987). The difference in the semantic structure of English and the indigenous languages is another complicating factor.

\section{The language culture in mathematics classrooms in South Africa}

Adler (2001) identifies three different language scenarios in multilingual mathematics classes:

- Firstly, the urban-suburban areas where there is a strong English environment and many different main languages are found.

- Secondly, the additional language situation of the urban or township contexts, with less English in the environment, a strong regional language and different indigenous languages present.

- Thirdly, a foreign language situation where the learners mostly hear English only at school and most of the learners have the same main language. This is often found in the rural areas.
The focus of this article will be on the foreign and additional language situations, as these are situations where the use of the main language as aid may be the most viable.

Two language strategies are currently implemented. The first strategy is to use only English in the teaching and learning of mathematics. This strategy is for example found where the teacher cannot speak the indigenous language or where many different indigenous languages are present in a class. Improving the learners' English proficiency is the main instrument to overcome situations where a varying proficiency in English complicates teaching and learning. In the meantime, teachers cope with learners' different levels of English proficiency by using different techniques to overcome communication problems. They for instance circumvent language by using a minimum of words and concentrating on symbolic language. Some teachers avoid such topics as linear programming and word problems. Another technique is to use safe talk such as "ritualisation", where questions are put to the class as a group, who then answer in a chorus (Hornberger \& Chick, 2001). This is 'face saving' because learners who do not know the answers can effectively hide in the group. Such a situation invariably creates an impression that everybody understands (Heller \& Martin-Jones, 2001).

In the second main strategy, namely codeswitching, both the main language(s) of the learners and English are used to facilitate understanding. Adler (2001) and Setati (2002) contributed by describing the nature of existing code-switching practices in multilingual mathematics classrooms. The discussions on the different purposes for which code-switching is used, as described by Setati (2002), give valuable insights into code-switching practices. Heller and Martin-Jones (2001, pp. 9-11) identify "front stage" and "back stage" use of the main language. Front stage describes the phenomenon where the main language is used to facilitate understanding, while "back stage" describes the situation where the main language is used only for giving instructions or in the affective domain, for example to encourage or discipline learners.

Some techniques that facilitate understanding are used in both the "English only" and codeswitching strategies. The technique of recasting provides the learner with examples of how to use 
mathematical terminology and synonyms in different sentences (Khisty, 1995). Revoicing, where the teacher listens to the learners' mathematical talk and revoices their expressions, leads them towards correct and more formal mathematical discourse (Setati \& Adler, 2000). Another technique is the use of the etymology and morphology of words, e.g. "sigma", which originates from the Greek letter "s" to indicate sum, or "co-interior angles" where "co" means together and "interior" inside.

A more recent development is the use of multilingual mathematics dictionaries of which three are worth mentioning here. The Multilingual Mathematics Dictionary for Grade 1 to 6 (Department of Arts and Culture, 2003) supplies a thousand existing mathematical terms in all eleven languages, mainly for teaching in primary school. The set of Bilingual Explanatory Maths Dictionaries (Fricke \& Meyer, 2005) give only the English terminology with explanations of the terminology in both English and an indigenous language (available for isiZulu, Setswana, Sesotho sa Leboa and Thsivenda). Understanding Concepts in Mathematics and Science (Young et al., 2005), supplies selected mathematics and science terminology in English, Xhosa, Zulu and Afrikaans, with a comprehensive discussion of the each term aided by illustrations. These dictionaries are important aids to code-switching and signify attempts to cope with the lack of formalised terminology in the indigenous languages.

The most recent development in the field of teaching in the multilingual classrooms is the research by Setati et al. (2007) on a new pedagogy for teaching and learning of mathematics in multilingual classrooms. The pedagogy focuses on a problem-centred strategy that includes a language strategy resembling the scaffolding proposed in this paper. Notes were given in both English and the relevant indigenous languages, but the English mathematical terminology was not translated. The use of the language was meant to be 'invisible' in the sense that the focus was on the mathematics, not on the language. Although the written material was made available in the learners' indigenous languages and code-switching was taking place, attention was not drawn to use of the language. In this study however, the terminology is translated and the focus is on how learners and teachers experienced the use of two languages.

These recent developments are summarised in Figure 1 and the place of the proposed scaffold is indicated.

Language in the multilingual Mathematics classroom

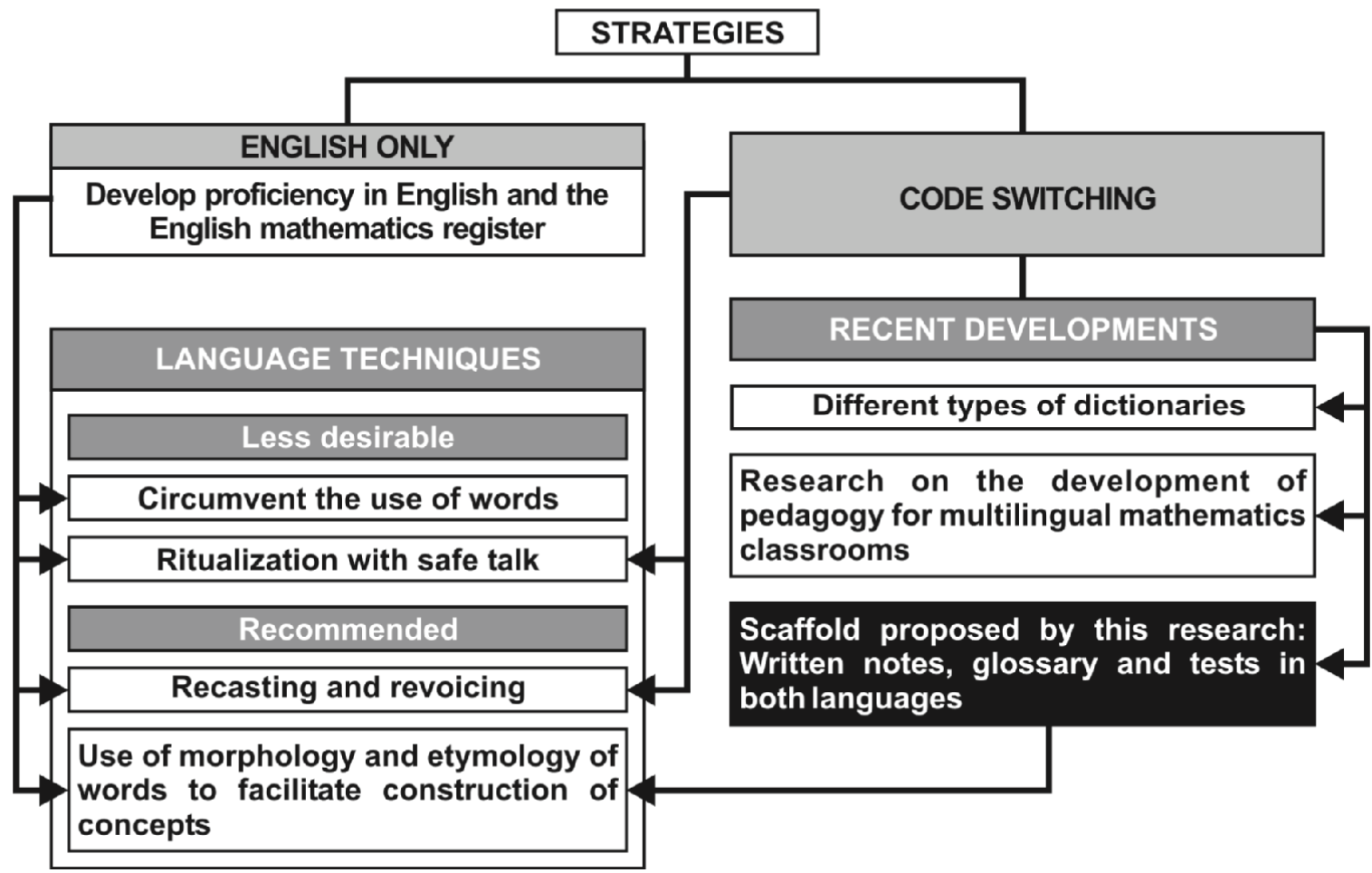

Figure 1: Strategies, techniques and recent developments 


\section{The empirical research}

In this qualitative study an intervention was made, involving code-switching between English and Setswana. Important features of the intervention were that the code-switching was supported by notes, a glossary with the main mathematical terminology of the unit, as well as tests set in both languages.

\section{The design of the geometry unit used in the intervention}

The intervention entailed the teaching of a geometry unit that included examples of worksheets for Grade 8 learners. An English/Setswana glossary of the most important terminology was composed for the learners to refer to while doing classwork and homework. Learners were not required to memorise the Setswana terminology, but could use the glossary as a reference in tests.

Setswana linguists from The Translation World CC did the translation of the unit and also created new terminology where no Setswana terminology existed. The Translation World CC does translations of mathematics texts for various role players in the market of school mathematics. Figure 2 shows some examples of the terminology in the glossary.

\begin{tabular}{|ll|}
\hline Straight lines & Mela e e tlhamaletseng \\
Common arm & Letsogo-gotlhe \\
Adjacent angles & Dikhutlomabapi \\
Vertically opposite angles & Dikhutlotsepamo-tebagano \\
Transversal & Molakgabaganyo \\
Horizontal line & Mola o o rapameng \\
Alternate angles & Dikhutlo-thefosano \\
Corresponding angles & Dikhutlo-tsamaelano \\
Co-interior angles & Dikhutlogare mmogo \\
Parallel lines & Mela e e bapileng \\
\hline
\end{tabular}

Figure 2: Examples of the terminology in the glossary

As the content of the notes consisted of many diagrams and short sentences, it was decided to put the sentences directly below each other, as illustrated in Figure 3.

Measure the width of each pair of parallel lines at different places.

Lekanya bophara ba para nngwe le nngwe e e bapileng mo mafelong a a farologaneng.

What do you find? $\backslash O$ bona eng?

Figure 3: An example of notes in two languages

\section{Research procedures and results}

The geometry unit was used as learning material in an intervention in Grade 8 classes at one rural school (School A) and one township school (School B) from the North West province in South Africa. Both schools were selected on the basis of convenience and feasibility. One Grade 8 teacher at each school agreed to teach the geometry unit and they became partners in the research. It took the teacher in School A five weeks and the teacher in School B four weeks to teach the geometry unit. Case studies were done at the two schools. It consisted of class visits with field notes and semistructured interviews with both a sample of learners from the classes where the intervention took place and the two teachers. All interviews were tape recorded and transcribed. Learners' interviews were translated from Setswana into English.

\section{School A}

School A is a well-organised but under-resourced combined school in a rural area. There was only one Grade 8 class with 33 learners, 31 of the learners' home language was Setswana and two isiXhosa. Four learners, namely, Joseph, Sanna, Lina, and Stephen, were selected for interviews. A range of different academic profiles were selected based on their mathematics, Setswana and English marks. The fifth learner, Gladys, was selected because she was one of the two learners whose home language was isiXhosa. The purpose of this was to look into the position of a learner that lives in a mainly Setswana environment, but whose home language is not Setswana.

The home language of the teacher, Miriam, was Setswana. She had 17 years teaching experience. She enjoyed teaching mathematics, but felt she was struggling a bit with the geometry teaching. Before the intervention Miriam's language policy was to teach mathematics in English and to switch to Setswana only when learners really did not understand. From the class visits during the intervention it was observed that the communication among the learners, arranged in groups, was subdued and mostly in Setswana. The teacher paid a great deal of individual attention to the learners. She asked the learners individually to read the notes to her in both languages, while at her table. Some of the learners read the notes in English fluently, but others could not manage well in English, while reading fluently in Setswana. 
When Miriam introduced new terminology, she initially explained the Setswana terminology, and also used the morphology of the terminology to explain the concepts in Setswana. She then introduced the formal English terminology and also coined sentences that she often repeated e.g. "the sum of the co-interior angles is 180 degrees." While teaching Miriam habitually used Setswana with code-mixing, using the English terminology as well as these coined sentences during a mainly Setswana explanation. Learners mostly answered questions in English, but it seemed as if English was a foreign language to many of the learners, because their communication in English would consist only of "yes" or "no" or the coined English mathematical phrases.

\section{The views of the teacher at School A}

Before the intervention, Miriam expressed the view that the learners' English was not very good "but they are trying." She stated that it was sometimes difficult for the learners to do their mathematics in English because they did not always understand the questions, therefore it would help them if they could learn in both languages. She expressed the view that new Setswana terminology would help some learners, but for others it would be difficult "because learners are not equal."

Mary was very enthusiastic about the geometry unit and expressed herself as follows after the intervention:

This unit has helped us a lot. Me and the learners. I called mister M. one day to come and witness them. Then he was so grateful to see what the learners have done. He was very, very happy.

Yes, I think that the language also contributed because I used their language to explain.

Although Miriam found the Setswana terminology more difficult than she expected, she said she used the Setswana terminology to explain the concepts, for example:

Dikuthlo-tsaemalano ... Dia tsamalana. That means they are the same, they are in the same position.

This was also apparent during the class visits. According to Miriam, the code-switching was of great value to the learners, but the Setswana terminology was difficult. She was of opinion that the learners preferred the English terminology, as well as to use English in their answers to questions in class and in tests. This was true for some of the learners, as can be seen in the interviews. Miriam also thought that the learners did not really use the glossary. The interviews with the learners revealed that this assumption was actually incorrect.

\section{Interviews with the learners at School A}

A senior teacher conducted the interviews in Setswana in collaboration with the researcher. The teacher gave feedback to the researcher of what the learners were saying, so that the researcher could monitor and direct further questions. Learners were asked to comment on the notes, terminology, glossary, and tests given in both languages. These interviews were later transcribed, translated and interpreted.

Although all the learners were in favour of the notes and glossary, two views could be discerned. Some learners preferred the English, but also saw the benefits of the dual use of the languages to enhance their understanding. The other learners depended more heavily on the Setswana, but realised that they also need the English because they have been trained in English for a long time.

The first view was expressed as follows by Lina:

I understand the geometry better in English, teacher.

She also commented on the glossary:

If you don't understand it in English you may be able to understand it in Setswana.

Stephen commented:

I understand it in English, but in Setswana I don't understand it well. English is just fine.

But also:

Setswana makes things easy. English should be used with Setswana explanations

About the tests he said:

I can't do mathematics in Setswana because we have been taught the subject for quite a long time in English.

The second view was expressed the clearest by Joseph:

I would like to be taught mathematics in English and Setswana. It is necessary to have the notes and list in those languages because some learners do not understand all the English words.

I was in the position to understand the teacher. 
Furthermore, he also wanted the tests in Setswana, and maintained that the Setswana terminology was easier to understand. However, he had to concede that the glossary was needed:

Because the teacher writes things in Setswana, the English words are needed. Yes teacher even in Setswana.

Gladys expressed a common view among the learners about the notes by saying: "Where I did not understand, I used Setswana to understand" and stated that the glossary was necessary because "you can read it in short." Sanna indicated that she sometimes knows concepts but cannot express herself: "If I don't remember what a straight line is in English - then I can refer to Setswana." Gladys's home language was not Setswana, but it was clear from the interview that her main language has become Setswana. Although their language at home was Xhosa, she was firm in her conviction that she is more fluent in Setswana. This was possibly because she lived in a Setswana environment and learned Setswana at school.

The picture that emerged from the interviews was that all the learners felt that they benefited from these language aids. This class is an example of an ideal situation for code-switching between Setswana and English with written work as scaffold. Only one main language has to be considered which makes code-switching easier and notes have to be translated into only one language.

\section{School B}

School B is a township school that is a large wellequipped secondary school. There were five Grade 8 classes with two mathematics teachers, Vusi and Peter. Before the intervention, Vusi and Peter were interviewed together. However, after Vusi studied the content of the geometry unit, he decided not to participate. He did not feel confident to teach the geometry unit using the Setswana mathematics register. Peter was willing to participate.

Four learners were interviewed at School B. Though the intention originally was to select learners whose home language is Setswana, it became clear that this would not be a true reflection of the situation at School B since the learners at this school had a mixed language profile. The learners were therefore only selected based on their academic profile in the same manner as in School A, without taking into account their home language. This resulted in a random selection of home languages. As it came about, only one learner's home language was Setswana, namely Sam. Thandi's home language was isisXhosa, and Thabo's home languages were Sesotho/Setswana. The fourth learner, Lebo's home language was Sepedi. He was transferred to School B in Grade 8 from a Sepedi primary school.

The home language of the teacher, Peter, was isiZulu, as was the main language of the primary school he attended. His secondary schooling was at a Setswana school and he has been teaching at School B for nine years. He felt confident about teaching mathematics. The class consisted of 56 learners. Before the intervention, the classes were usually conducted mainly in English, although Peter sometimes did use Setswana. During the intervention, Peter explained more in Setswana than usually, but still used a fair amount of English and the English terminology was front staged. During class visits, it was observed that he used the morphology of the new Setswana terminology as a tool when explaining concepts. He explained new concepts in Setswana and then linked it to the English:

It's like the 'alternate' its like (the teacher) is given another chance (to explain), its almost like that, and then you say 'refosano ... tefosano'. You say 'tefosano ... dikutlho tefosano' and then tefosano is like from the word 'refosano' its like 'just for two', you see. Some of the words that they are acquainted to.

Learners answered questions freely and good communication was established. The learners seemed to have mastered the Setswana terminology and answered questions mainly in Setswana. The communication among the learners was mainly in Setswana. With 56 learners in the class, there was not time to pay individual attention to all the learners.

\section{Views of the teacher at School B}

Peter expressed the opinion that his learners were not very good in English and therefore it was sometimes difficult for the learners to understand the mathematics concepts when the LoLT was English. He felt that it would be easier for the learners if they could be taught in Setswana only, because the concepts will be easier for them in their main language. However, he was of the opinion that if the two languages are used simultaneously, like in code-switching and with the notes in both languages, it will create confusion. 
After the intervention, Peter said that it took time to get used to the Setswana mathematics register ("the lingo itself"). He was a bit ashamed to be seen teaching in Setswana. Learners who visited the class "wanting that and that" were amazed to hear him teaching mathematics in Setswana and he had to explain why. Even so, Peter "enjoyed" himself. He expressed himself as follows about switching to Setswana:

It was something very positive, I enjoyed myself. It gave me another chance of trying to put the knowledge or the concept very clear for them.

The learners participated more in the class than usual and he commented: "It makes it much easier for them to understand than in English."

$\mathrm{He}$ is of opinion that it was beneficial for the learners to have the Setswana notes and glossary as aid, especially because some of the Setswana terminology was new and the learners did not know it.

\section{Interviews with the learners at School B}

The interviews at school B were conducted by an experienced Sestwana interviewer from the university in collaboration with the researcher. The interviews were conducted mainly in Setswana in the same manner, and with the same set of questions, as was done at School A. Learners were asked to give comments on the notes, terminology, glossary, and tests supplied in both languages.

It seemed that Thandi and Lebo needed the dual presentation of languages and they felt that Setswana was very important. Thandi was positive about all the features of the dual language presentation:

The Setswana helped me, I understand Setswana much better than English.

She was also emphatic that she needed the Setswana in the tests.

Although Lebo was Sepedi, he also appreciated the dual use of language. His: "Sharp - it helped me", came over very enthusiastically. He also repeated the refrain that was heard at the rural school: "If I do not understand the English term - I refer to the Setswana word list." He liked the terminology in Setswana, but for the test he preferred English. His comment "In English because I'm used to English terms" highlighted that this was a new experience for the learners and the fact that they previously used only English in written work played an important role in their views.

Sam and Thabo had mixed feelings. Although Sam said:

I feel much good because the usage of both English and Setswana make it better to understand

he did not like the Setswana mathematical terminology itself. He stated that he did not need the glossary, and want the test in English only. $\mathrm{He}$ remarked:

they are much better in English. Setswana terms give me problems.

Thabo was more non-committal and commented on the code-switching: "It was very interesting" and on the notes and Setswana terminology: "it was not a problem to have two languages." $\mathrm{He}$ showed his interest in the dual language representation finally by saying that the tests should be in both languages.

The learners' different home languages did not seem to have a great impact on how much benefit they felt they had gained from the Setswana aids. From the interviews, it became clear that Setswana has become both Thabo and Thandi's main language, possibly because they attended schools with main language Setswana from Grade 1. Lebo, who has started in a school where the main language is Setswana only in Grade 8 also felt strongly that he benefited. This may be because he has encountered Setswana earlier, as was established from the interview, and because Sepedi is a related language.

None of the learners indicated that the use of the two languages together was confusing, as Peter feared. On the contrary, they found it useful. As they did not understand the mathematical Setswana or the English perfectly, they could refer to both languages to make sense of the notes, and consequently maximise understanding.

\section{Discussion}

The teachers found the Setswana terminology difficult, as could be expected as they have been using English terminology during their entire careers. However, they did use the morphology of terminology to link the concepts to words and concepts that the learners knew. Although some of the learners preferred the English terminology and found the Setswana terminology difficult, the main 
impression is that the learners' view is that they benefited from the availability of the Setswana notes and the glossary. The learners differed in their views on whether Setswana/English questions in the tests were necessary, but most of them welcomed it. It was significant that all the learners made it clear that they used both the English and the Setswana to clarify what they did not understand in the other language. This suggests that the dual use of languages is useful so that the learners can continuously oscillate between the two, using understanding in one language to support learning in the other.

The purpose of the study was not to establish whether English as LoLT should be substituted by Setswana. The learners' preference for English terminology and answering questions in English is therefore not a negative feature, because in the end the aim is to facilitate the journey to the formal mathematical register of English.

Although the study was a qualitative study and therefore the results cannot be generalised, valuable information has been gained concerning the views and experiences of these learners and teachers. It was positively established that it benefited most learners to have these Setswana language-aids available, involving code-switching, English/Setswana notes, a glossary, and tests as a scaffold to enhance understanding.

\section{Conclusion}

An evolutionary process can be seen in research on language matters in mathematics classrooms in South Africa. It started with reports on informal code-switching that was initiated by the teachers themselves and continued with more structured investigations into the language journeys. Dictionaries of varied structures started to appear to aid the code-switching, with the newest development being the investigations of Setati's team into developing a new pedagogy for multilingual classrooms, one of the features being the use of study material in the learners' different main languages as well as in English. Vusi's reaction showed that some teachers were not ready to use code-switching with written work as support. However, Peter and Miriam showed that some teachers are ready and even enthusiastic to try this strategy.

It seems that the issue of Setswana terminology must not be forced. Both teachers and some of the learners found the Setswana terminology difficult. However, these learners' and the teachers' struggle with the indigenous mathematical terminology is not surprising, since both teachers and learners are accustomed to the usage of the mathematical terminology in English only. Therefore, it seems that the way to go at the moment is to use support materials in the indigenous language with the mathematical terminology mainly in English. This was the language strategy in the research on a pedagogy for multilingual mathematics classes done by Setati et al. (2007).

On the other hand, the teachers both used the morphology of words like dikuthlomabapi and dikhutlo-thefosano in their teaching and found it useful and some learners welcomed the Setswana terminology. Because it is an evolutionary process, the time can be foreseen when the need for terminology in Setswana may be more pressing. The use of the techniques of recasting, revoicing and facilitating conceptualisation by using the morphology and etymology of words in the main language of learners will also be more viable if such terminology is available. As a result, research into finding methods to create meaningful terminology for mathematics in Setswana where such terminology does not exist, may be indicated as an area of future research. Although this will be a slow process the development of mathematical registers in indigenous languages may be one of the by-products of the development of this kind of pro-active scaffold model of code-switching.

\section{References}

Adler, J. (2001). Teaching mathematics in multilingual classrooms. Dordrecht: Kluwer Academic.

Costello, J. (1991). Teaching and learning mathematics 11-16. London: Routledge.

Department of Arts and Culture (2003). Multilingual mathematics dictionary. Pretoria: National Language Service.

Fricke, I., \& Meyer, L. (2005). Bilingual explanatory maths dictionary - English. Isizulu. Pretoria: Clever books. (Also in Sesotho, Sesotho sa Leboa, Setswana and Yshivenda.)

Gentner, D., \& Goldin-Meadow, S. (Eds.) (2003). Language in mind. Advances in the study of language and thought. Cambridge: MIT Press.

Heller, M., \& Martin-Jones, M. (Eds.) (2001). Voices of authority: Education and linguistic difference. Westport, Conn.: Ablex Publishing. 
Hornberger, N. H., \& Chick, J. K. (2001). Coconstructing school safetime: Safetalk practices in Peruvian and South African classrooms. In M. Heller \& M. Martin-Jones (Eds.), Voices of authority: Education and linguistic difference (pp. 31-55). Westport, Conn.: Ablex Publishing.

Khisty, L. L. (1995). Making inequality: Issues of language and meanings in mathematics teaching with Hispanic students. In G. Secada, E. Fennema \& L. Adajian (Eds.), New directions for equity in mathematics education (pp. 279-285). New York: Cambridge University Press.

Orton, A., \& Frobisher, L. (1996). Insights into teaching mathematics. London: Cassell.

Pimm, D. (1987). Speaking mathematically. Communication in mathematics classrooms. London: Routledge.

Pimm, D. (1991). Communicating mathematically. In K. Durkin \& B. Shire (Eds.), Language in mathematical education: Research and practice (pp. 18-24). Philadelphia: Open University Press.

Sai, K. P. (1994). Doing and talking in primary mathematics. Pythagoras, 34,15-19.

Setati, M. (2002). Language practices in intermediate multilingual mathematics classrooms. Unpublished doctoral dissertation, University of the Witwatersrand.

Setati, M., \& Adler, J. (2000). Between languages and discourses: Language practices in primary multilingual mathematics classrooms in South Africa. Educational Studies in Mathematics, 43, 243-269.
Setati, M., Adler, J., Reed, Y., \& Bapoo, A. (2002). Code switching and other language practices in mathematics, science and English language classroom in South Africa. In J. Adler \& Y. Reed (Eds.), Challenges of teacher development: An investigation of take up in South Africa (pp. 7292). Pretoria: Van Schaik Publishers.

Setati, M., Molefe, T., Duma, B., Nkambule, T., Mpalami, N., \& Langa, M. (2007). Towards pedagogy for teaching Mathematics in multilingual classrooms. Marang symposium CD, Wits Centre for Maths and Science Education, University of the Witwatersrand.

Shunk, D. H. (1996). Learning theories (2nd ed.). Englewood Cliffs, N.J.: Prentice Hall.

Usiskin, Z. (1996). Mathematics as language. In P. C. Elliot, \& M. J. Kenney (Eds.), Communication in mathematics: K-12 and beyond. 1996 Yearbook (pp 231-243). Reston: NCTM.

Vorster, J. A. (2005). The influence of terminology and support materials in the main language on the conceptualisation of geometry learners with Limited English Proficiency. Unpublished master's thesis, Potchefstroom University for C.H.E.

Vygotsky, L. S. (1962). Thought and language. (Edited and translated by Eugenia Hanfmann and Gertrude Vakar.) New York: M.I.T. Press.

Young, D., van der Vlugt, J., \& Qanya, S., et al. (2005). Understanding concepts in mathematics and science: A multilingual learning and teaching resource book in English, isiXhosa, isiZulu, Afrikaans. Cape Town: Maskew Miller Longman. 